\title{
Adubação nitrogenada na cultura do milho safrinha irrigado em plantio direto
}

\author{
Juliana Aparecida Souza (1); Salatiér Buzetti (2); Marcelo Carvalho Minhoto Teixeira Filho $\left({ }^{1 *}\right)$; \\ Marcelo Andreotti ( $\left.{ }^{2}\right)$; Marco Eustáquio de Sá $\left({ }^{2}\right)$; Orivaldo Arf $\left({ }^{2}\right)$
}

(') Universidade Estadual Paulista "Julio de Mesquita Filho" (UNESP), Faculdade de Engenharia de Ilha Solteira (FEIS), Programa de Pós-Graduação em Agronomia/Sistemas de Produção, 15385-000 Ilha Solteira (SP).

(2) UNESP/FEIS, Departamento de Fitotecnia, Tecnologia de Alimentos e Sócio-Economia, Caixa Postal 31, 15385-000 Ilha Solteira (SP).

(*) Autor correspondente: mcmtf@yahoo.com.br

Recebido: 29/abr./2010; Aceito: 23/nov./2010.

\begin{abstract}
Resumo
A cultura do milho safrinha é uma importante alternativa econômica para a entressafra. Contudo, esta cultura remove grandes quantidades de nitrogênio $(\mathrm{N})$ e necessita de manejo adequado da adubação nitrogenada para obtenção de elevadas produtividades. $\mathrm{O}$ objetivo deste trabalho foi avaliar o efeito de fontes, doses e épocas de aplicação de $\mathrm{N}$ nas características agronômicas e na produtividade de grãos de milho safrinha irrigado. O experimento foi realizado em Selvíria (MS), em Latossolo Vermelho Distroférrico, irrigado por aspersão e sob plantio direto, em 2007 e 2008. O delineamento experimental utilizado foi o de blocos casualizados, com quatro repetições, dispostos em um esquema fatorial $5 \times 3 \times 2$, sendo: cinco doses de $N\left(0,50,100,150\right.$ e $200 \mathrm{~kg} \mathrm{ha}^{-1}$ ), três fontes de N (sulfonitrato de amônio com inibidor de nitrificação, sulfato de amônio e uréia) aplicadas na semeadura ou em cobertura, no estádio de seis folhas. As fontes de $\mathrm{N}$ proporcionaram semelhantes produtividades de grãos de milho safrinha irrigado e com efeito similar quanto às características agronômicas estudadas. A antecipação da adubação nitrogenada foi viável, assim como a tradicional aplicação de $\mathrm{N}$ em cobertura. $\mathrm{O}$ incremento das doses de $\mathrm{N}$ aumentou o teor de $\mathrm{N}$ foliar, os números de grãos por fileira e por espiga, e consequentemente, a produtividade de grãos de milho safrinha irrigado. $\mathrm{O}$ incremento das doses de nitrogênio aumentou a produtividade de grãos de milho safrinha cultivado após milho até a dose de $150 \mathrm{~kg} \mathrm{ha}^{-1}$ de $\mathrm{N}$, em média, independentemente da época de aplicação e da fonte de N.
\end{abstract}

Palavras-chave: Zea mays, doses de nitrogênio, fontes de nitrogênio, épocas de aplicação.

\section{Nitrogen fertilization on second crop corn in no till irrigated}

\section{Abstract}

The second corn crop is an important economical alternative for agriculture. As this crop removes great amounts of $\mathrm{N}$, it is necessary an appropriate nitrogen fertilization management for obtaining high yields. The objective of this work was to evaluate the effect of sources, doses and times of nitrogen application on agronomic characteristics and productivity of corn grains in an irrigated second crop. The experiment was accomplished in Selvíria, Mato Grosso do Sul State, in a red dystrophic Latosol irrigated by sprinkle and conducted under no till, in 2007 and 2008. The experiment was arranged in randomized complete blocks design, with 4 repetitions, disposed in a factorial scheme $5 \times 3 \times 2$, being: five doses of $N(0,50,100,150$ and $200 \mathrm{~kg} \mathrm{ha}^{-1}$ ), three sources of $\mathrm{N}$ (ammonium sulfonitrate with nitrification inhibitor, ammonium sulfate and urea) applied at sowing or totally at sidedressing in the stage of 6 leaves. The $\mathrm{N}$ sources provided similar grain yield. The nitrogen application at sowing was viable, as well as the traditional application of $\mathrm{N}$ at sidedressing. The increment of $\mathrm{N}$ doses increased the leaf $\mathrm{N}$ content, the number of grains per line and per ear and consequently the grain yield. The $\mathrm{N}$ doses increased the grain yield of the second crop up to $150 \mathrm{~kg} \mathrm{ha}^{-1}$ of $\mathrm{N}$, independently of application time or $\mathrm{N}$ sources.

Key words: Zea mays, nitrogen doses, nitrogen sources, application times. 
O cultivo do milho safrinha iniciou-se no Estado do Paraná, tem sido viável economicamente para o produtor, e tornou-se importante nas regiōes Sudeste e Centro-Oeste. Contudo, para obtençáo de elevadas produtividades econômicas, esta cultura remove grandes quantidades de $\mathrm{N}$, necessita de manejo adequado da adubaçáo nitrogenada para complementar a quantidade de $\mathrm{N}$ fornecida pelo solo e reduzir gastos desnecessários com a compra do adubo nitrogenado.

Resultados experimentais obtidos por vários autores, sob diversas condiçôes de solo, clima e sistemas de cultivo, mostram respostas generalizadas do milho à adubação nitrogenada; cerca de $70 \%$ a $90 \%$ dos ensaios de adubação com milho, realizados em campo, no Brasil, são responsivos à aplicação de nitrogênio (Cruz et al., 2005). Contudo, ressalta-se que a eficiência da adubação depende, dentre outros fatores, das condiçóes climáticas, do tipo de solo e da capacidade de extração de nutrientes pelas plantas, durante o cultivo (Neumann et al., 2005).

A época de aplicação de $\mathrm{N}$ pode variar sendo comum a aplicação, na semeadura, de parte do $\mathrm{N}$ recomendado e o restante em cobertura, quando as plantas estáo com 4 a 8 folhas (Pöttker e Wiethölter, 2004). Entretanto, YAMADA (1995) afirma ser possível a aplicação de uma quantidade maior de $\mathrm{N}$ na semeadura, discordando de Coelho et al. (1991), que recomendam o fornecimento de $\mathrm{N}$ em uma única aplicação em cobertura para doses de até $100 \mathrm{~kg} \mathrm{ha}^{-1}$, em solos de textura argilosa. CASAGRANDE e Fornasieri Filho (2002) não verificaram diferença da forma de aplicação do $\mathrm{N}$ (todo na semeadura ou todo em cobertura) e do incremento de doses de $\mathrm{N}$ na produtividade de grãos de milho na safrinha. Segundo Lara Cabezas et al. (2005), em anos com condiçóes climáticas normais, a antecipação da adubação nitrogenada em pré-semeadura ou semeadura seria mais favorável, com predomínio da atividade imobilizadora pela biomassa do solo. Entretanto, segundo estes autores, as condiçóes climáticas mais extremas (falta ou excesso de água) estariam, aparentemente, favorecendo a adubação em cobertura (imobilização restrita pela falta de palha, no primeiro caso, e acentuada nitrificação seguida de lixiviação do nitrato, no segundo).

Neste contexto, o estudo de fontes nitrogenadas é muito importante para a agricultura, uma vez que estes fertilizantes têm comportamento diferenciado quando aplicados ao solo, em especial para perdas de N. A uréia pode proporcionar menor eficiência no fornecimento de $\mathrm{N}$ às plantas quando aplicada na superfície do solo em funçấo de perdas por volatilização de $\mathrm{NH}_{3}$. Já o sulfato de amônio propicia perdas desprezíveis de $\mathrm{N}-\mathrm{NH}_{3}$ quando o pH do solo é inferior a 7. Porém, este fertilizante pode teoricamente ter sua eficiência reduzida por lixiviação de nitratos (CANTARELla, 2007).

$\mathrm{O}$ adubo nítrico amoniacal, sulfonitrato de amônio, possui $26 \%$ de $\mathrm{N}$ total, na sua maior parte na forma amo- niacal (18,5\% amoniacal e 7,5\% na forma nítrica) e 12\% de enxofre. Este fertilizante compõe de moléculas DMPP (3,4 dimetilpirazolfosfato) que atuam na inibição de nitrificação (Los Fertilizantes, 2006). A inibição do processo de nitrificação é interessante, pois mantém o $\mathrm{N}$ na forma de $\mathrm{NH}_{4}^{+}$, o qual fica mais tempo disponível para as plantas reduzindo, assim, as perdas de $\mathrm{N}$ por lixiviação do $\mathrm{NO}_{3}$. Lara Cabezas et al. (2005) verificaram que a aplicaçấo do sulfato de amônio, independentemente da época de aplicaçáo (pré-semeadura e cobertura) proporcionou maior produtividade de grãos de milho, em relação à aplicação da uréia.

Embora muitos trabalhos de pesquisa tenham sido realizados nos últimos anos, muitas dúvidas existem sobre quanto, como e quando realizar a adubação nitrogenada, principalmente no cultivo do milho safrinha. Logo, a realização de estudos que avaliem a melhor época, fonte e modo de aplicação de nitrogênio se faz necessária para melhor aproveitamento desse recurso. Assim, o objetivo deste trabalho foi avaliar o efeito de fontes, doses e épocas de aplicação do nitrogênio nas características agronômicas e na produtividade de grãos de milho safrinha irrigado, cultivado em Selvíria (MS).

O experimento foi instalado em área experimental, localizada no município de Selvíria (MS), com coordenadas geográficas de $51^{\circ} 22^{\circ}$ de longitude Oeste e $20^{\circ} 22$ de latitude Sul e altitude de $335 \mathrm{~m}$. O solo é classificado como Latossolo Vermelho Distrófico, textura argilosa (EMBRAPA, 2006), o qual foi originalmente ocupado por vegetação de cerrado e cultivado por culturas anuais há mais de 25 anos. A classificação climática da regiâo, de acordo com Köppen é Aw, definido como tropical úmido com estaçáo chuvosa no verão e seca no inverno. A temperatura média anual é de $23,5^{\circ} \mathrm{C}$, a precipitaçáo pluvial média anual é de $1370 \mathrm{~mm}$ e a umidade relativa do ar média anual entre $70 \%$ e $80 \%$. Os valores de precipitação pluvial $(\mathrm{mm})$, umidade relativa do ar (\%) e temperatura média $\left({ }^{\circ} \mathrm{C}\right)$ da área de cultivo durante a condução do experimento em 2007 e 2008 constam na figura 1 .

O delineamento experimental utilizado foi o de blocos casualizados, com quatro repetiçôes, dispostos em um esquema fatorial $5 \times 3 \times 2$, sendo: cinco doses de $\mathrm{N}(0$, $50,100,150$ e $200 \mathrm{~kg} \mathrm{ha}^{-1}$ ), três fontes de $\mathrm{N}$ (sulfonitrato de amônio com inibidor de nitrificaçáo - $\mathrm{SN}$, sulfato de amônio e uréia) aplicadas na semeadura ou em cobertura, no estádio de seis folhas. As dimensóes das parcelas foram de $5 \mathrm{~m}$ de comprimento, mais $2 \mathrm{~m}$ de bordadura com quatro linhas espaçadas de $0,90 \mathrm{~m}$ e 5,4 sementes por metro, tanto em 2007 como em 2008.

O solo da área experimental compóe-se de 420, 50 e $530 \mathrm{~g} \mathrm{~kg}^{-1}$, respectivamente, de areia, silte e argila. Os atributos químicos deste solo na profundidade de $0,0 \mathrm{a}$ $0,20 \mathrm{~m}$ foram determinados antes da instalação do experimento, segundo método proposto por RaIJ e QuagGio (1983) e com os seguintes resultados: $36 \mathrm{mg} \mathrm{dm}^{-3} \mathrm{de} P$ 
(resina); $18 \mathrm{mg} \mathrm{dm}^{-3}$ de $\mathrm{S}\left(0,01 \mathrm{~mol} \mathrm{~L}^{-1} \mathrm{de} \mathrm{Ca}\left(\mathrm{H}_{2} \mathrm{PO}_{4}\right)_{2}\right.$. $\left.\mathrm{H}_{2} \mathrm{O}\right)$; $31 \mathrm{~g} \mathrm{dm}^{-3}$ de M.O.; 5,4 de $\mathrm{pH}\left(\mathrm{CaCl}_{2}\right) ; \mathrm{K}, \mathrm{Ca}$, $\mathrm{Mg}, \mathrm{H}+\mathrm{Al}=4,2 ; 31,0 ; 17,0$ e $29,0 \mathrm{mmol}_{\mathrm{c}} \mathrm{dm}^{-3}$ respectivamente e $64 \%$ de saturação por bases. Com base nesses atributos químicos do solo e na tabela de recomendação de adubação para a cultura do milho, para o Estado de São Paulo, conforme descrito em Cantarella et al. (1997), calculou-se a adubação básica no sulco de semeadura, constante para todos os tratamentos, que foi de $70 \mathrm{~kg} \mathrm{ha}^{-1}$ de $\mathrm{P}_{2} \mathrm{O}_{5}$ (superfosfato simples) e $40 \mathrm{~kg} \mathrm{ha}^{-1} \mathrm{de}$ $\mathrm{K}_{2} \mathrm{O}$ (cloreto de potássio). A adubação em semeadura de $\mathrm{N}$ foi realizada logo após a semeadura da cultura, posicionando o adubo próximo ao sulco $(5 \mathrm{~cm})$. A adubação nitrogenada de cobertura foi realizada em 23 de julho de 2007 e 26 de junho de 2008, no estádio de seis folhas verdadeiras, aplicando o adubo nas entrelinhas, a uma distância de 0,20 $\mathrm{m}$ da linha de semeadura da cultura. Ambas foram realizadas manualmente e logo após a adubação, a área foi irrigada por aspersão, com uma lâmina de água de aproximadamente $14 \mathrm{~mm}$ para minimizar as perdas de nitrogênio por volatilização da amônia, que ocorre devido à hidrólise da uréia. Esta operação é comum nos sistemas de produçáo de grãos irrigados, quando se aplica a uréia.

Nos dois cultivos de milho safrinha, os tratamentos foram instalados na mesma área experimental onde se utiliza o sistema plantio direto há 9 anos. A cobertura morta da área estava com um adensamento por volta de $20 \%$. O histórico de cultivos desta área foi: feijão (2006), milho (safra 2006/2007), milho (safrinha 2007), milho (safra 2007/2008) e milho safrinha (2008). A área foi dessecada utilizando o herbicida glyphosate (1500 $\mathrm{g} \mathrm{ha}^{-1}$ do i.a.). A semeadura do híbrido simples AG 5020 foi realizada mecanicamente, em 15 de junho de 2007 e 15 de maio de 2008. Em seguida, a área foi irrigada por aspersão, por meio de pivô central para promover a germinação das sementes. As plântulas emergiram 5-7 dias após a semeadura.

O fornecimento de água foi efetuado de três em três dias ou quando necessário por aspersão por meio de um sistema fixo de irrigação do tipo pivô central. O volume de rega da irrigação foi de $14 \mathrm{~mm}$ e o volume total irrigado durante o ciclo da cultura foi igual a $602 \mathrm{~mm}$. O manejo de plantas daninhas foi efetuado com a aplicaçáo da mistura de herbicidas atrazine + nicosulfuron $(3,5 \mathrm{~kg}$ $\mathrm{ha}^{-1}+1,25 \mathrm{~L} \mathrm{ha}^{-1}$ do i.a.) em pós-emergência. $\mathrm{O}$ controle da lagarta do cartucho foi efetuado com aplicação da mistura spinosad + triflumurom $\left(36,0+24,0 \mathrm{~g} \mathrm{ha}^{-1} \mathrm{do}\right.$ i.a.). A colheita do milho foi realizada manualmente $\mathrm{e}$ individualmente por unidade experimental, em 2007 e 2008, respectivamente, aos 135 e 125 dias após a emergência das plantas. $\mathrm{O}$ material colhido foi trilhado mecanicamente.

Foram realizadas as seguintes avaliaçôes: a) teor de nitrogênio foliar, analisado no terço médio de 20 folhas da base da espiga; por ocasiáo do florescimento feminino (Cantarella et al., 1997). Da área útil de cada parcela foram coletadas cinco espigas ao acaso para contagem manual de: b) número de fileiras de grãos na espiga; c) número de grãos na fileira da espiga; d) número de grãos por espiga; e) massa de cem grãos, determinada em balança analítica, com teor de água dos grãos corrigidos para 130 $\mathrm{g} \mathrm{kg}^{-1}$ (base úmida); f) produtividade de grãos, determinada pela coleta das plantas contidas nas 2 linhas centrais $(10 \mathrm{~m})$ de cada parcela. Após a trilhagem mecânica, os grãos foram quantificados e os dados transformados em $\mathrm{kg} \mathrm{ha}^{-1}$ a $130 \mathrm{~g} \mathrm{~kg}^{-1}$ (base úmida).

Os dados foram submetidos à análise de variância, e as médias comparadas pelo teste de Tukey a 5\% de probabilidade para o efeito das fontes de $\mathrm{N}$ e de épocas de aplicação de $\mathrm{N}$, e ajustada a equaçóes de regressão para o efeito das doses de N. Para análise estatística foi utilizado o programa de análise estatística SANEST (ZoNTA e Machado, 1986). Procedeu-se também, às análises de correlação para produtividade de grâos versus todas as características agronômicas, individualmente.

No experimento, constatou-se que a fonte de $\mathrm{N}$ sulfato de amônio proporcionou maior teor de $\mathrm{N}$ na folha em relação à uréia e ao sulfonitrato de amônio com inibidor de nitrificação - SN, apesar de não diferir significativamente deste último em 2007 (Tabela 1). Também Lourente et al. (2007), trabalhando com culturas antecessoras, doses e fontes de $\mathrm{N}$ nos componentes de produção do milho, verificaram menores incrementos no teor de $\mathrm{N}$ foliar para uréia quando comparados à aplicação de sulfato de amônio. Contudo, vale ressaltar que no cultivo 2007, todos os teores de $\mathrm{N}$ observados estáo abaixo dos valores descritos como adequado (27,0 - 35,0 g de $\mathrm{N} \mathrm{kg}^{-1}$ de matéria seca) segundo Cantarella et al. (1997). No cultivo 2008, apesar do teor de $\mathrm{N}$ foliar médio $\left(26,4 \mathrm{~g}\right.$ de $\mathrm{N} \mathrm{kg}^{-1}$ de matéria seca) estar um pouco abaixo do considerado adequado, observaram-se teores adequados nas doses de 100, $150 \mathrm{e}$ $200 \mathrm{~kg} \mathrm{ha}^{-1} \mathrm{de}$ N. Fernandes et al. (2005), estudando os efeitos de doses de nitrogênio em seis cultivares de milho em plantio direto, em Selvíria (MS), também constataram teores de $\mathrm{N}$ na folha inferiores ao descrito como adequado para a maioria das doses e cultivares estudados.

Com relação às épocas de aplicação do $\mathrm{N}$, observa-se que a aplicação do $\mathrm{N}$ em cobertura proporcionou maior teor de $\mathrm{N}$ foliar do que a aplicação do $\mathrm{N}$ em semeadura, em 2008 (Tabela 1). Esse fato ocorreu porque a aplicação do $\mathrm{N}$ em cobertura é realizada mais próxima do florescimento da cultura, período de coleta das folhas da espiga para análise do teor de $\mathrm{N}$ foliar. Quanto às doses de $\mathrm{N}$, estas influenciaram o teor de $\mathrm{N}$ foliar de forma quadrática tanto em 2007 como em 2008, com ponto de máximo acúmulo de $\mathrm{N}$ sendo atingido, respectivamente, com a estimativa de aplicação de 170 e $196 \mathrm{~kg} \mathrm{ha}^{-1}$ de N. Entretanto, MAR et al. (2003) constataram maior concentraçáo de $\mathrm{N}\left(28,0 \mathrm{~g} \mathrm{~kg}^{-1}\right)$ na folha de milho safrinha com a dose 
Tabela 1. Teores de N foliar, N. ${ }^{\circ}$ de fileiras de grãos na espiga, N.o de grãos na fileira da espiga, N. ${ }^{\circ}$ total de grãos na espiga, massa de cem grãos, produtividade de grãos de milho safrinha em função de fontes, épocas de aplicação e doses de N. Selvíria (MS), 2007 e 2008

\begin{tabular}{|c|c|c|c|c|c|c|}
\hline Tratamento & $\begin{array}{l}\text { Teor de } N \\
\text { foliar }\end{array}$ & $\begin{array}{l}\text { N. }{ }^{\circ} \text { de fileiras } \\
\text { de grãos }\end{array}$ & $\begin{array}{l}\text { No de grãos na } \\
\text { fileira }\end{array}$ & $\begin{array}{c}\text { N. }{ }^{\circ} \text { de grãos } \\
\text { na espiga }\end{array}$ & $\begin{array}{l}\text { Massa de cem } \\
\text { grãos }\end{array}$ & $\begin{array}{l}\text { Produtividade } \\
\text { de grãos }\end{array}$ \\
\hline & $\mathbf{g ~ k g}^{-1}$ & & & & g & $\mathrm{kg} \mathrm{ha}^{-1}$ \\
\hline & \multicolumn{6}{|c|}{ Cultivo em 2007} \\
\hline
\end{tabular}

Fontes de $\mathrm{N}$

\begin{tabular}{|c|c|c|c|c|c|c|}
\hline $\mathrm{SN} *$ & $21,6 a$ & $14,15 a$ & $32,55 a$ & $441,15 a$ & $28,25 a$ & $6316 a$ \\
\hline Sulfato de amônio & $21,0 a$ & $13,95 a$ & $32,10 a$ & $454,10 a$ & $28,15 a$ & $6664 a$ \\
\hline Uréia & $18,6 b$ & $14,10 a$ & $31,30 a$ & $454,15 a$ & $27,25 a$ & $6279 a$ \\
\hline D.M.S. (5\%) & 1,7 & 0,35 & 1,30 & 18,30 & 1,15 & 603 \\
\hline \multicolumn{7}{|l|}{ Épocas de aplicação } \\
\hline Semeadura & $20,5 a$ & $14,05 a$ & $32,00 a$ & $449,55 a$ & $27,75 a$ & $6601 a$ \\
\hline Cobertura & $20,1 \mathrm{a}$ & $14,10 a$ & $31,95 a$ & $450,00 a$ & $28,00 a$ & $6240 a$ \\
\hline D.M.S. (5\%) & 1,2 & 0,20 & 0,75 & 12,45 & 0,80 & 411 \\
\hline \multicolumn{7}{|l|}{ Doses de $\mathrm{N}\left(\mathrm{kg} \mathrm{ha}^{-1}\right)$} \\
\hline 0 & $15,5^{(1)}$ & $14,15^{\text {ns }}$ & $29,75^{(2)}$ & $420,90^{(3)}$ & $25,65^{(4)}$ & $4807^{(5)}$ \\
\hline 50 & 19,3 & 13,90 & 32,54 & 445,20 & 27,55 & 6108 \\
\hline 100 & 22,4 & 14,10 & 32,45 & 459,60 & 27,70 & 7086 \\
\hline 150 & 22,9 & 14,00 & 33,20 & 464,25 & 29,00 & 7275 \\
\hline 200 & 21,3 & 14,15 & 32,05 & 459,00 & 29,50 & 6825 \\
\hline Média geral & 20,3 & 14,00 & 32,00 & 450,00 & 28,00 & 6420 \\
\hline \multirow[t]{2}{*}{ C.V. (\%) } & 16,00 & 3,65 & 6,50 & 7,60 & 7,85 & 17,65 \\
\hline & \multicolumn{6}{|c|}{ Cultivo em 2008} \\
\hline
\end{tabular}

Fontes de $\mathrm{N}$

\begin{tabular}{|c|c|c|c|c|c|c|}
\hline SN & $26,0 b$ & $13,80 a$ & $35,09 a$ & $484,45 a$ & $32,14 a$ & $6104 a$ \\
\hline Sulfato de amônio & $27,1 \mathrm{a}$ & $13,50 a$ & $35,47 a$ & $477,86 a$ & $33,45 a$ & $6333 a$ \\
\hline Uréia & $26,0 b$ & $13,80 a$ & $34,66 a$ & $471,67 a$ & $31,25 a$ & $6157 a$ \\
\hline D.M.S. (5\%) & 1,0 & 0,30 & 1,28 & 18,70 & 2,55 & 411 \\
\hline \multicolumn{7}{|l|}{ Épocas de aplicação } \\
\hline Semeadura & $25,6 b$ & $13,70 a$ & $35,17 a$ & $480,90 a$ & $32,06 a$ & $6154 a$ \\
\hline Cobertura & $27,2 \mathrm{a}$ & $13,60 a$ & $34,96 a$ & $475,10 a$ & $32,50 a$ & $6243 a$ \\
\hline D.M.S. (5\%) & 0,7 & 0,20 & 0,87 & 12,72 & 1,04 & 279 \\
\hline \multicolumn{7}{|l|}{ Doses de $N\left(\mathrm{~kg} \mathrm{ha}^{-1}\right)$} \\
\hline 0 & $21,3^{(6)}$ & $13,80^{\text {ns }}$ & $33,82^{(7)}$ & $465,20^{\text {ns }}$ & $29,60^{(8)}$ & $4562^{(9)}$ \\
\hline 50 & 24,8 & 13,60 & 34,78 & 472,80 & 30,78 & 5549 \\
\hline 100 & 27,3 & 13,70 & 34,87 & 475,00 & 32,30 & 6330 \\
\hline 150 & 28,9 & 13,50 & 36,09 & 485,90 & 33,96 & 6981 \\
\hline 200 & 29,6 & 13,80 & 35,78 & 491,10 & 34,73 & 7568 \\
\hline Média geral & 26,4 & 14,00 & 35,00 & 478,00 & 32,00 & 6198 \\
\hline C.V. (\%) & 7,55 & 3,80 & 6,85 & 7,35 & 8,90 & 12,45 \\
\hline
\end{tabular}

* SN - sulfonitrato de amônio com inibidor de nitrificaçáo. Médias seguidas de letra iguais, na coluna, náo diferem entre si pelo teste de Tukey, em nível de $5 \%$ de probabilidade. ns: Não significativo pela análise de regressão. ${ }^{(1)},{ }^{(2)},{ }^{(3)},{ }^{(4)},{ }^{(5)},{ }^{(6)},{ }^{(7)},{ }^{(8)} \mathrm{e}{ }^{(9)}$ se referem às equaçóes de regressão abaixo.

(1) $\mathrm{Y}=15,5835+0,0848 \mathrm{~N}-0,00025 \mathrm{~N}^{2} \quad\left(\mathrm{R}^{2}=0,99 \mathrm{e} \mathrm{PM}=170 \mathrm{~kg} \mathrm{ha}^{-1} \mathrm{de} \mathrm{N}\right)$

${ }^{(2)} \mathrm{Y}=29,8295+0,0455 \mathrm{~N}-0,00016 \mathrm{~N}^{2} \quad\left(\mathrm{R}^{2}=0,96 \mathrm{e} \mathrm{PM}=142 \mathrm{~kg} \mathrm{ha}^{-1} \mathrm{de} \mathrm{N}\right)$

(3) $\mathrm{Y}=421,0127+0,5724 \mathrm{~N}-0,0018 \mathrm{~N}^{2} \quad\left(\mathrm{R}^{2}=0,99\right.$ e $\left.\mathrm{PM}=159 \mathrm{~kg} \mathrm{ha}^{-1} \mathrm{de} \mathrm{N}\right)$

(4) $\mathrm{Y}=26,0429+0,0183 \mathrm{~N}$

(5) $\mathrm{Y}=4766,6667+34,9260 \mathrm{~N}-0,1226 \mathrm{~N}^{2} \quad\left(\mathrm{R}^{2}=0,99 \mathrm{e} \mathrm{PM}=142 \mathrm{~kg} \mathrm{ha}^{-1} \mathrm{de} \mathrm{N}\right)$

(6) $\mathrm{Y}=21,3030+0,0785 \mathrm{~N}-0,0002 \mathrm{~N}^{2} \quad\left(\mathrm{R}^{2}=0,85\right.$ e $\left.\mathrm{PM}=196 \mathrm{~kg} \mathrm{ha}^{-1} \mathrm{de} \mathrm{N}\right)$

(7) $\mathrm{Y}=34,0292+0,0104 \mathrm{~N} \quad\left(\mathrm{R}^{2}=0,99\right)$

(8) $\mathrm{Y}=29,5935+0,0269 \mathrm{~N} \quad\left(\mathrm{R}^{2}=0,99\right)$

(9) $\mathrm{Y}=4709,2250+14,8880 \mathrm{~N} \quad\left(\mathrm{R}^{2}=0,99\right)$ 
de $145 \mathrm{~kg} \mathrm{ha}^{-1}$ de $\mathrm{N}$; tal diferença se deve aos híbridos utilizados e ao cultivo após a cultura da soja, que deve ter fornecido $\mathrm{N}$ às plantas de milho.

Os números de fileiras de grãos na espiga, de grãos na fileira da espiga e de grãos na espiga não foram influenciados significativamente pelas fontes de $\mathrm{N}$ e épocas de aplicação de N, nos dois cultivos (Tabela 1). Por outro lado, SANGoI et al. (2007) constataram em solo com alto teor de matéria orgânica, que a aplicação de todo o N $(100 \mathrm{~kg}$ $\left.\mathrm{ha}^{-1}\right)$ antes ou durante a semeadura do milho diminuiu o número de grãos por espiga.

A elevaçáo das doses de $\mathrm{N}$ aumentou o número de grãos na fileira da espiga até a dose de $142 \mathrm{~kg} \mathrm{ha}^{-1}$ de N, em 2007 e linearmente em 2008. Consequentemente, o número de grãos na espiga também foi influenciado pelas doses de $\mathrm{N}$, aumentando até a dose de $159 \mathrm{~kg} \mathrm{ha}^{-1} \mathrm{de} \mathrm{N} \mathrm{em}$ 2007 e linearmente em 2008. Por outro lado, o número de fileiras de grãos na espiga não foi afetado pelo incremento das doses de N. Casagrande e Fornasieri Filho (2002) não verificaram efeito de doses de $\mathrm{N}\left(0,30,60\right.$ e $90 \mathrm{~kg} \mathrm{ha}^{-1}$ de $\mathrm{N}$ ), na forma de uréia, aplicadas na semeadura ou após a emergência (estádio de 5 a 6 folhas) no número de fileiras de grãos por espiga e de grãos por espiga de milho safrinha. Esse efeito pode ser explicado pelas diferentes condiçóes de solo e de ambiente nas diferentes áreas experimentais, além da grande variabilidade entre os híbridos disponíveis atualmente, quanto às características estudadas.

$\mathrm{Na}$ tabela 1, observa-se que as fontes de $\mathrm{N}$ náo influenciaram a massa de cem grãos. Oliveira e Caires (2003) não constataram diferença entre a uréia, aplicada na superfície ou com incorporação, e o sulfato de amônio, aplicado na superfície em SPD. As épocas de aplicação de $\mathrm{N}$ também não diferiram entre si para tal componente da produção, em 2007 e 2008. As doses de $\mathrm{N}$ influenciaram a massa de cem grãos de forma positiva, tanto no cultivo 2007 como em 2008, ajustando-se a funçóes lineares crescentes. As respostas da massa de cem ou mil grãos à adubação nitrogenada na literatura são muito variáveis. Oliveira e Caires (2003) também verificaram aumento linear da massa de cem grãos e que tal componente de produçáo foi decisivo para aumentar a produtividade de grãos, utilizando as doses de 0, 30, 60, 90 e $120 \mathrm{~kg} \mathrm{ha}^{-1}$ de N. Já Casagrande e Fornasieri Filho (2002) não constataram efeito de doses e de épocas de aplicação de $\mathrm{N}$ na massa de cem grãos. Escosteguy et al. (1997), comparando diferentes doses de $\mathrm{N}$ que variavam de 0 a $160 \mathrm{~kg}$ ha $^{-1}$, também não obtiveram diferenças significativas em relação a esta avaliação.

$\mathrm{O}$ sulfato de amônio, o $\mathrm{SN}$ e a uréia não diferiram significativamente para a produtividade de grãos de milho safrinha, nos dois cultivos (Tabela 1). Esta ausência de resposta das fontes de $\mathrm{N}$, provavelmente ocorreu devido ao fato de logo após sua aplicação ter sido efetuada a irrigação no experimento, reduzindo assim as perdas por volatilização, principalmente da $\mathrm{NH}_{3}$ proveniente da uréia. As fontes de $\mathrm{N}$ também tiveram comportamento semelhante devido à baixa precipitaçáo pluvial registrada no período de cultivo (Figura 1), posto que o experimento foi desenvolvido em safrinha. Portanto, náo houve significativa lixiviação de $\mathrm{N}$, além disso, a irrigação no experimento foi controlada e não teria provocado lixiviação de nitrato. Provavelmente, por isso o fertilizante SN (com inibidor de nitrificação) não tenha se sobressaído.

Oliveira e CAIRes (2003) não constataram diferença na produção de milho entre a uréia aplicada na superfície, ou com incorporação, e o sulfato de amônio na superfície. Entretanto, Lara Cabezas et al. (2005) verificaram que a aplicação do sulfato de amônio, independentemente da época de aplicação (pré-semeadura e cobertura) proporcionou acréscimos significativos (em média $847 \mathrm{~kg} \mathrm{ha}^{-1}$ ) de grãos de milho, em relação à aplicação da uréia. Segundo estes autores, a maior eficiência do $\mathrm{N}$ do sulfato de amônio e o indicador de imobilização explicam a maior produtividade do milho quando utilizada esta fonte em pré-semeadura e cobertura. Além disso, o enxofre presente no sulfato de amônio deve ter contribuído à melhor resposta pela planta.

A antecipação de toda a adubação nitrogenada para semeadura não diferiu significativamente para produtividade de grãos de milho safrinha, em relaçáo à aplicação de $\mathrm{N}$ em cobertura, no estágio de seis folhas (Tabela 1). Casagrande e Fornasieri Filho (2002) também não verificaram diferença da forma de aplicação do $\mathrm{N}$ (todo na semeadura ou todo em cobertura) na produtividade de grãos de milho na safrinha. Esses resultados concordam com os relatados por YAMADA (1995), que cita ser possível a aplicação de uma quantidade maior de $\mathrm{N}$ na semeadura. Por outro lado, diferem dos citados por Coelho et al. (1991), quando recomendam que o fornecimento de $\mathrm{N}$ deve ser feito em uma única aplicação em cobertura para doses de até $100 \mathrm{~kg} \mathrm{ha}^{-1}$, em solos de textura argilosa. Por sua vez, Ros et al. (2003) não constataram diferença entre a aplicação de $\mathrm{N}$ total na semeadura ou em cobertura para produtividade de grãos de milho, em sistema plantio direto em solo argiloso. Portanto, a prática da aplicaçáo antecipada deste nutriente foi eficaz neste estudo, pois o milho safrinha foi cultivado em um período em que tradicionalmente ocorrem poucas chuvas nesta região, como demonstra a figura 1. Além disso, essa eficácia provavelmente ocorreu porque o solo onde o experimento foi realizado possui boa fertilidade e drenagem, é bastante argiloso, e com bom teor de matéria orgânica.

As doses de $\mathrm{N}$ influenciaram a produtividade de gráos de milho safrinha, se ajustando à função quadrática com a máxima produtividade sendo alcançada com a estimativa de $142 \mathrm{~kg} \mathrm{ha}^{-1}$ de N (aumento de $50 \%$ em relação ao tratamento sem N), no cultivo 2007 (Tabela1). Já no cultivo 2008, a produtividade cresceu linearmente de 4.562 a $7.568 \mathrm{~kg} \mathrm{ha}^{-1}$ de grãos, ou seja, a dose de $200 \mathrm{~kg} \mathrm{ha}^{-1}$ de N, em relação ao tratamento sem N, au- 


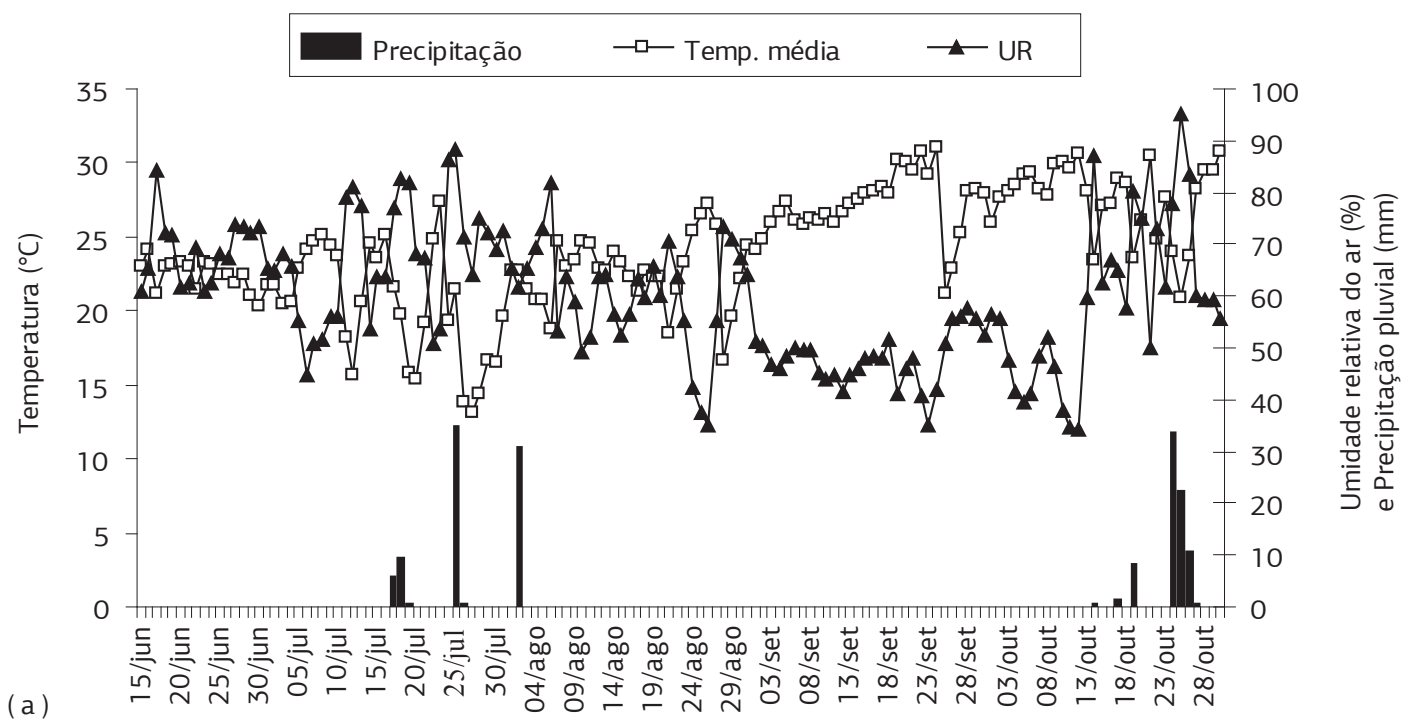

Período de condução do experimento (dias)

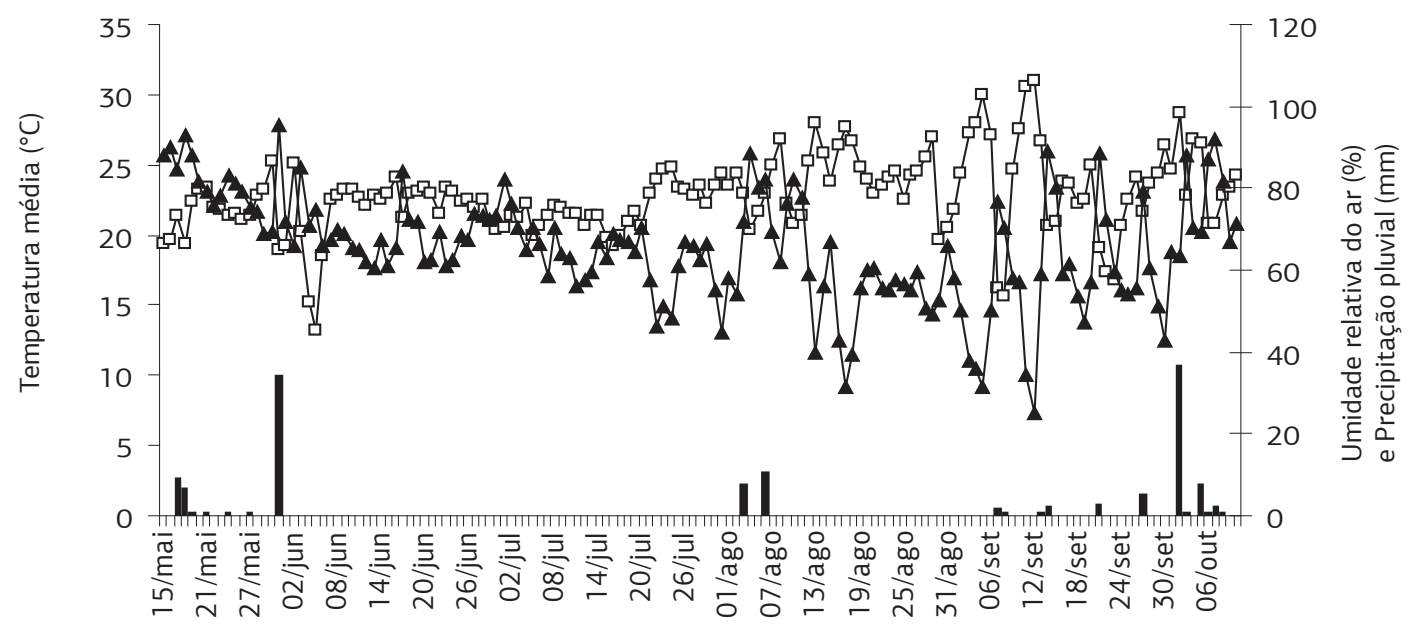

(b )

Período de condução do experimento (dias)

Figura 1. Precipitação pluvial $(\mathrm{mm})$, temperatura média $\left({ }^{\circ} \mathrm{C}\right)$ e umidade relativa do ar $(\%)$ durante a condução do experimento. Selvíria (MS), em 2007 (a) e 2008 (b).

mentou a produtividade do milho em $66 \%$. Diferentes respostas em diferentes anos de cultivo também foram observadas por Pereira et al. (1999), quando citam que os principais fatores determinantes dessa variação são: a época de semeadura, as condiçóes climáticas e os níveis de $\mathrm{N}$ dos solos.

$\mathrm{O}$ solo também contribui fornecendo $\mathrm{N}$ às plantas. A produtividade média da testemunha nos dois anos de cultivo foi de $4.684 \mathrm{~kg} \mathrm{ha}^{-1}$, o que demonstra haver disponibilidade de $\mathrm{N}$ no solo, provenientes de outras fontes não controladas e da decomposição microbiana da matéria orgânica. Semelhantemente Escosteguy et al. (1997) observaram que a contribuição do $\mathrm{N}$ do solo foi bastante significativa, pois a produtividade da testemunha foi de
$5.812 \mathrm{~kg} \mathrm{ha}^{-1}$, em Latossolo Vermelho-Escuro Distrófico, com teor de matéria orgânica de $35 \mathrm{~g} \mathrm{dm}^{-3}$.

De modo geral, para as características agronômicas avaliadas no cultivo 2007, independentemente da fonte nitrogenada utilizada e da época de aplicaçáo do fertilizante, a dose ótima de $\mathrm{N}$ varia de $142 \mathrm{a} 170 \mathrm{~kg} \mathrm{ha}^{-1}$, em média $150 \mathrm{~kg} \mathrm{ha}^{-1}$, valor próximo ao estimado para a produtividade de grãos. No cultivo 2008, a aplicação de $200 \mathrm{~kg} \mathrm{ha}^{-1}$ de $\mathrm{N}$ que proporcionou a maior produçáo, promoveu um incremento na produtividade de grãos de apenas $8 \%$ em relação à dose de $150 \mathrm{~kg} \mathrm{ha}^{-1}$, que aumentou $53 \%$ em relaçáo ao tratamento sem N. Portanto, a dose de $150 \mathrm{~kg} \mathrm{ha}^{-1}$ de $\mathrm{N}$ seria a recomendada. Este resultado assemelha-se aos observados para cultura do 
milho irrigado (entre 120 e $150 \mathrm{~kg} \mathrm{ha}^{-1} \mathrm{de} \mathrm{N}$ ), descrita por Souza et al. (2003). Mar et al. (2003) também observaram resposta positiva da adubação nitrogenada no milho safrinha, sendo a maior produtividade de grãos obtida com a dose de $120 \mathrm{~kg} \mathrm{ha}^{-1}$ de N. Fernandes et al. (2005), avaliando a eficiência de doses de $\mathrm{N}(0,30$, 90 e $180 \mathrm{~kg} \mathrm{ha}^{-1}$ ) em seis cultivares de milho irrigado, na região de Selvíria (MS), verificaram que a máxima produtividade média foi alcançada com a estimativa de $110 \mathrm{~kg} \mathrm{ha}^{-1}$ de $\mathrm{N}$ para uma produtividade de $6.000 \mathrm{~kg}$ $\mathrm{ha}^{-1}$ de grãos. Por outro lado, Casagrande e Fornasieri Filho (2002) não constataram efeito de doses de N (0, 30,60 e $90 \mathrm{~kg} \mathrm{ha}^{-1}$ de N) aplicadas na forma de uréia, na produtividade de grãos de milho safrinha.

A produtividade de grãos se correlacionou positivamente com o teor foliar de $\mathrm{N}(0,94 ; 0,98)$, o número de grãos na fileira $(0,85 ; 0,90)$, o número de grãos na espiga $(0,95 ; 0,87)$ e a massa de cem grãos $(0,83 ; 0,95)$, respectivamente, em 2007 e 2008. Esses valores evidenciam a importância do $\mathrm{N}$ tanto no que se refere ao estado nutricional da planta quanto a sua influência positiva no aumento do número e da massa de grãos de milho irrigado, proporcionando assim maior produtividade de grãos no cultivo safrinha. Segundo Mohammadi et al. (2003), a massa do grão e o número de grãos por espiga foram os componentes mais importantes na prediçáo da produtividade de grãos de híbridos de milho, constatada por meio da análise de trilha.

As fontes de $\mathrm{N}$ sulfonitrato de amônio com inibidor de nitrificação, sulfato de amônio e uréia proporcionaram semelhantes produtividades de grãos de milho safrinha irrigado e com efeito similar quanto às características agronômicas estudadas.

A antecipação da adubação nitrogenada foi viável, assim como a tradicional aplicaçáo de $\mathrm{N}$ em cobertura na cultura do milho safrinha.

$\mathrm{O}$ incremento das doses de $\mathrm{N}$ aumentou o teor de $\mathrm{N}$ foliar, o número de grãos por fileira e por espiga, e consequentemente, a produtividade de grãos de milho safrinha irrigado.

$\mathrm{O}$ incremento das doses de nitrogênio aumentou a produtividade de grãos de milho cultivado após milho até a dose de $150 \mathrm{~kg} \mathrm{ha}^{-1}$ de $\mathrm{N}$, em média, independentemente da época de aplicação e da fonte de $\mathrm{N}$.

\section{AGRADECIMENTOS}

À Fundação de Amparo à Pesquisa do Estado de São Paulo - FAPESP, pelo apoio financeiro (Processo N. ${ }^{\circ}$ 2006/04277-3) e pela concessão da bolsa da primeira autora (Processo N.o 2007/05659-0) e ao Conselho Nacional de Desenvolvimento Científico e Tecnológico - CNPq, pela concessão da bolsa de produtividade do segundo, quarto e sexto autores.

\section{REFERÊNCIAS}

CANTARELLA, H. Nitrogênio. In: NOVAIS, R. F; ALVAREZ, V. H.; BARROS, N. F.; FONTES, R. L. F.; CANTARUTTI, R. B.; NEVES, J. C. L. (Ed.). Fertilidade do Solo. Viçosa: Sociedade Brasileira de Ciência do Solo, 2007. p.551-594.

CANTARELlA, H.; RAIJ, B. van; CAMARGO, C.E.O. Cereais. In: RAIJ, B. van; CANTARELLA, H.; QUAGGIO, J.A.; FURLANI, A.M.C. Recomendaçôes de calagem e adubação para o Estado de Sáo Paulo. Campinas: IAC, 1997, 285p. (Boletim técnico, 100)

CASAGRANDE, J.R.R.; FORNASIERI FILHO, D. Adubação nitrogenada na cultura do milho safrinha. Pesquisa Agropecuária Brasileira, v.37, p.33-40, 2002.

COELHO, A.M.; FRANÇA, G.E.; BAHIA FILHO, A.F.C.; GUEDES, G.A.A. Balanço de nitrogênio (15N) em um Latossolo Vermelho-Escuro, sob vegetação de cerrado, cultivado com milho. Revista Brasileira de Ciência do Solo, v.15, p.187-193, 1991.

CRUZ, J.C.; PEREIRA, F.T.F.P.; PEREIRA FILHO, I.A.; COELHO, A.M. Resposta de cultivares de milho à adubaçáo nitrogenada em cobertura. Sete Lagoas: EMBRAPA. Dezembro, 2005. p.65 (Comunicado Técnico 116)

EMPRESA BRASILEIRA DE PESQUISA AGROPECUÁRIA. Sistema brasileiro de classificação de solos. 2.ed. Rio de Janeiro: EMBRAPA/CNPSo, 2006. 306p.

ESCOSTEGUY, P.A.V.; RIZZARDI, M.A.; ARGENTA, G. Doses e épocas de aplicação de nitrogênio em cobertura na cultura do milho em duas épocas de semeadura. Revista Brasileira de Ciência do Solo, v.21, p.71-77, 1997.

FERNANDES, F.C.S.; BUZETTI, S.; ARF, O.; ANDRADE, J.A.C. Doses, eficiência e uso de nitrogênio por seis cultivares de milho. Revista Brasileira de Milho e Sorgo, v.4, p.195-204, 2005.

LARA CABEZAS, W.A.R.; ARRUDA, M.R.; CANTARELLA, H.; PAULETTI, V.; TRIVELIN, P.C.O.; BENDASSOLLI, J.A. Imobilização de nitrogênio da uréia e do sulfato de amônio aplicado em pré-semeadura ou cobertura na cultura de milho, no sistema plantio direto. Revista Brasileira de Ciência do Solo, v.29, p.215-226, 2005.

LOS FERTILIZANTES y su uso. 4.ed. Roma: FAO/IFA, 2002, p.87. Disponível em: <www.fertilizer.org>. Acesso em: 5 set. 2006.

LOURENTE, E.R.P.; ONTOCELLI, R.; SOUZA, L.C.F.; GONÇALVES, M.C.; MARCHETTI, M.E.; RODRIGUES, E.T. Culturas antecessoras, doses e fontes de nitrogênio nos componentes de produção do milho. Acta Scientiarum Agronomy, v.29, p.55-61, 2007.

MAR, G.D.; MARCHETTI, M.E.; SOUZA, L.C.F.; GONÇALVES, M.C.; NOVELINO, J.O. Produção do milho safrinha em função de doses e épocas de aplicação de nitrogênio. Bragantia, v.62, p.267-274, 2003.

MOHAMMADI, S.A.; PRASANNA, B.M.; SINGH, N.N. Sequential path model for determining interrelationship among grain yield related characters in maize. Crop Science, v.43, p.16901697, 2003. 
NEUMANN, M.; SNDINI, I.E.; LUSTOSA, S.B.C.; OST, P.R.; ROMANO, M.A.; FALBO, M.K.; PANSERA, E.R. Rendimentos e componentes de produção da planta de milho (Zea mays L.) para silagem, em função de níveis de adubação nitrogenada em cobertura. Revista Brasileira de Milho e Sorgo, v.4, p.418-427, 2005.

OLIVEIRA, J.M.S.; CAIRES, E.F. Adubação nitrogenada em cobertura para o milho cultivado após aveia preta no sistema plantio direto. Acta Scientiarum Agronomy, v.25, p.351-357, 2003.

PEREIRA, S.L.; ARAÚJO, G.A.A.; SEDIYAMA, C.S.; VIEIRA, C.; MOSQUIM, P.R. Efeitos da adubação nitrogenada e molíbdica sobre a cultura do milho. Ciência e Agrotecnologia, v.23, p.790798, 1999.

PÖTTKER, D.; WIETHÖLTER, S. Épocas e métodos de aplicação de nitrogênio em milho cultivado no sistema plantio direto. Ciência Rural, v.34, p.1015-1020, 2004.

RAIJ, B. van; QUAGGIO, J.A. Métodos de análise de solo para fins de fertilidade. Campinas: IAC, 1983. 38p. (Boletim Técnico IAC, 81)
ROS, C.O.; SALET R.L.; PORN, R.L.; MACHADO, J.N.C. Disponibilidade de nitrogênio e produtividade de milho e trigo com diferentes métodos de adubação nitrogenada no sistema plantio direto. Ciência Rural, v.33, p.799-804, 2003.

SANGOI, L.; ERNANI, P.R.; SILVA, P.R.F. Maize response to nitrogen fertilization timing in two tillage systems in a soil with high organic matter content. Revista Brasileira de Ciência do Solo, v.31, p.507-517, 2007.

SOUZA, L.C.F.; FEDATTO, E.; GONÇALVES, M.C.; SOBRINHO, T.A.; HOOGERHEIDE, H.C.; VIEIRA, V.V. Produtividade de grãos de milho irrigado em funçáo da cultura antecessora e de doses de nitrogênio. Revista Brasileira de Milho e Sorgo, v.2, p.44-51, 2003.

YAMADA, T. Adubação nitrogenada do milho: como melhorar a eficiência? Informaçôes Agronômicas, Piracicaba, n.71, p.1-9, 1995.

ZONTA, E.P.; MACHADO, A.A. Sistema de análise estatística para microcomputadores - SANEST. Pelotas: UFPel, Instituto de Física e Matemática, 1986. 150p. 